DOI 10.37882/2500-3682.2020.07.11

\title{
О НЕКОТОРЫХ ПРОБЛЕМАХ ИСПОЛЬЗОВАНИЯ ЭЛЕМЕНТОВ ИСКУССТВЕННОГО ИНТЕЛЛЕКТА В ОБРАЗОВАТЕЛЬНОЙ И НАУЧНОЙ ДЕЯТЕЛЬНОСТИ В СОВРЕМЕННОЙ РОССИИ
}

\section{ABOUT SOME PROBLEMS OF USING ELEMENTS OF ARTIFICIAL INTELLIGENCE IN EDUCATIONAL AND SCIENTIFIC ACTIVITIES IN MODERN RUSSIA}

A. Evsiouk

Summary: This article argues why one should define intelligence not as an Essence, but as a property inherent in the Subject. A robot, a computer, like any other technical device, cannot be a subject of cognition in itself; artificial intelligence is not cosa in se, since it acts only as a consequence, a product of human existence. That is why, the constant dynamism, unpredictability of intelligence, the fundamental right to creative activity and mental errors, makes the study of the issue of artificial intelligence in the context of scientific research controversial in view of the fact that the reproduction of existing cognitive knowledge, and even the likely patterns of its production, cannot be considered a complete analogy of human scientific potential. The author of the article departs from comprehension of the obvious promise of progress that follows the globalization of artificial intelligence and focuses on the study of its relationship with the Personality and philosophical problems in a single conglomerate technology-science-educatio-man.

Keywords: artificial intelligence, science, education, personality, cognitiveness, existence.

\section{Введение}

K ак известно, «единого доктринального подхода к определению понятия искусственный интеллект и сущности этого явления пока не выработано» [1].

Затронутые в настоящем исследовании вопросы и предоставленная авторская оценка являются дискуссионными и открытыми для конструктивной критики и широкого обсуждения, учитывая их актуальность и важность для обеспечения устойчивого развития информационного общества. Исследования, посвященные конкурентоспособности и предотвращению интеллектуальной деградации человека в среде сосуществования с искусственным интеллектом (далее - ИИ), имеют значение для сохранения и развития будущей эволюции научного знания и образовательной среды. Мы относим себя к сторонникам оптимистического сценария и не видим повода для ментальной паники, так как окружающий мир автоматизируется

\author{
Евсюк Александр Владимирович \\ K.nсх.н., с.н.С., Военный университет Министерства \\ обороны Российской Федерачии, Москва
}

avev2020@bk.ru

Аннотация: В данной статье аргументируется, почему следует определять интеллект не как Сущность, а как свойство, присущее Субъекту. Робот, компьютер, как и любое другое техническое устройство, не могут быть субъектом познания сами по себе; искусственный интеллект не является cosa in se, так как выступает лишь следствием, продуктом человеческого бытия. Именно поэтому, постоянная динамичность, непредсказуемость интеллекта, принципиальное право на творческую деятельность и ментальные ошибки, делают изучение вопроса искусственного интеллекта в контексте научных изысканий и сферы образования спорным ввиду того, что воспроизведение имеющегося когнитивного знания, и даже вероятных схем его продуцирования, не может считаться полноценной аналогией человеческого научного потенциала. Автор статьи отходит от осмысления очевидной перспективности прогресса, который следует за глобализацией искусственного интеллекта и концентрируется на исследовании его соотношения с Личностью и имеющихся философских проблемах в экзистенции единого конгломерата техника-наука-образование-человек.

Ключевые слова: искусственный интеллект, наука, образование, личность, когнитивность, экзистенция. непрерывно: исчезновение одной части рабочих мест в сфере образования и науки, будет происходить одновременно с возникновением новых вакансий по другим профессиональным и секторальным направлениям.

Работа может приобрести иной, не рутинный характер - стать креативнее; будет формироваться не противостояние людей и машин, а их взаимопомощь. Подобная дискуссия уже сегодня инициирует высшие учебные заведения и предпринимателей искать образовательные решения и таланты для новых цифровых ролей; становится ясно, что значительное количество современных образовательных учреждений готовит «ненужных» в будущем специалистов, то есть тех, чьи знания и умения будут довольно успешно заменены системами, связанными с ИИ. Наряду с этим, «в настоящее время существует множество программ ИИ, помогающих в образовании, благодаря которым студенты, школьники и учителя получают огромную пользу» [2]. 
Именно поэтому модернизация системы образования должна осуществляться в новых направлениях, которые выйдут за рамки формирования узких компетенций и перейдут к модели планомерной адаптации к цифровизации, поставив задачу оптимизации путей нивелирования потенциальных рисков от масштабирования ИИ. Ведущие специалисты в данной области должны сконцентрироваться на том, чтобы результаты функционирования ИИ были научно, экономически и социально обоснованными, а не деструктивно-неконтролируемыми.

Как верно подмечают Пичужкина Д.Ю., Смекалова Е.С., «результаты внедрения ИИ в образовательную (и научную) среду неоднозначны, существуют свои плюсы и минусы, и большинство плюсов можно рассматривать как минусы, так и наоборот» [3, с. 620], поэтому в настоящей работе мы будем описывать исключительно собственное мнение, практически не ссылаясь на разрозненные дискуссии современности.

Основная часть. По нашему мнению, несмотря на темпы внедрения ИИ во все сферы, будущее образования и науки находится исключительно в руках человека, ведь любое знание, даже генерируемое искусственно, интерпретируется как результат осмысления человеческого опыта; наряду с перспективами, существует и проблемная сторона, так как ИИ дает не только положительные возможности в сфере образования и науки, но и такие, согласиться и смириться с которыми крайне трудно.

Те разработки в сфере ИИ и экспертных баз данных с чрезвычайно мощными возможностями, которые имеются на сегодняшний день, уже поставили под угрозу существования целый ряд профессий, однако, как уже было сказано выше, это не повод для паники, так как спектр проблем гораздо шире, чем банальная и вполне прогнозируемая замена человека в ряде практических и теоретических усилий. В контексте данной темы важно не осмысление перспективности прогресса, который следует за глобализацией ИИ, а исследование соотношения ИИ и личности, которые пока ещё неразрывно связаны в едином конгломерате техника-наука-образованиечеловек.

Философия науки определяет личность как познавательный субъект, однако, по нашему мнению, экзистенция человека не ограничивается когнитивной функцией. Только комбинация всех проявлений человеческих атрибутов (психико-психологических) может объективизировать существование интеллекта. Следует определять интеллект не как Сущность, а как свойство, присущее субъекту. Робот, как и любое техническое устройство, не могут быть субъектами познания сами по себе; ИИ не является cosa in se, так как выступает лишь следствием, продуктом человеческого бытия.
Если рассматривать данный вопрос через призму философского осмысления, то интеллект может быть определен в соответствии с наличием базовых признаков, которые описаны в соответствующей психологической литературе. Однако, даже наличие всех признаков интеллектуальности, не может быть достаточным основанием для подтверждения и аргументации способности разумного существа претендовать на полноценность того аспекта интеллекта, который может быть перспективен в плане эволюции научного знания. «Научная искра», «азарт учёного» и даже случайная ошибка (как и множество других чисто человеческих факторов) много раз за всю историю эволюции науки, приводили к смене научной парадигмы.

Сегодня же обоснована необходимость закономерного поддержания ускоренного развития ИИ, но только фрагментарно возможно предсказать, как оно в дальнейшем повернёт ход эволюции, не говоря уже о сегодняшнем влиянии на обычный уклад жизни, экономику, политику, образование и иные сферы.

Образование и научные изыскания неразрывно связаны. Нам импонирует классическое мнение, которое гласит, что профессия преподавателя требует творческого подхода, незаурядных психологических способностей и умения реагировать на вызовы времени и модификацию поведения новых поколений. Однако, в 2017 году в Военной академии США, известной также как Вест-Пойнт (U. S. Military Academy, West Point), уже успешно проведен эксперимент: человекоподобный робот «BINA48» выполнял функции преподавателя философии, прочитав несколько лекций, посвященных этическим суждениям и теории справедливой войны [4].

Анализ ряда отечественной литературы 2018-2020 годов, описывающей опыт деятельности российских вузов показал, что в «некоторых из них в качестве помощников и ассистентов активно используются более новые и технологичные инструменты. Это роботы телеприсутствия, роботы-учителя (Московский государственный технический университет имени Н.Э. Баумана, Московский технологический институт, Томский политехнический университет и ряд других), системы для конструирования роботов (Festo Didactic Mechatronics, Control Kit и LEGO Mindstorms)» [5].

Так, например, активно используются:

- учебные системы Festo Didactic Mechatronics, Control Kit и LEGO Mindstorms, представляющие собой набор программных блоков, моторов и датчиков для конструирования роботов;

- механические и электронные обучающие конструкторы для учебных лабораторий:fischertecnik, роботрек «Инженер»;

- роботы телеприсутствия: Romo, Double, Даша, R. Bot, Webot, Promobot; 
- роботы-учителя: «Пушкин» и SAYA; южнокорейские роботы Robosem, позволяющие педагогу удаленно вести уроки английского языка; роботы VANI, предназначенные для автономного обучения иностранным языкам, математике, физике, химии; роботы Edison - помощники учителей информатики (разработка австралийской компании Microbric);

- ассистент-преподаватель онлайн-курсов Джил Уотсон (США); российские роботы-учителя информатики, разработанные в вузах Казани и Томска; робот Алантим, используемый в качестве заместителя заведующего кафедрой робототехники Московского технологического института;

- помощники для людей с аутизмом (роботы Nao, Russel, KASPAR), роботы-посредники для обучающихся с ОВ3 (VGo for Remote Students, США) [6].

Очевидно, что единичные случаи не отражают будущую закономерность и в ближайшие десятилетия вряд ли роботизированная техника заменит преподавателей, однако эти примеры четко демонстрируют нам то, что ИИ имеет претенциозные намерения вторгнуться в образование и научную деятельность.

Неоспорим тот факт, что на студентов в образовательном процессе во многом оказывает влияние не сухой научный текст, а харизма преподавателя и совокупность его невербальных человеческих проявлений. Ранее область применения роботов в образовании была ограничена их использованием в качестве педагогических инструментов для сферы технических и математических наук, однако в 2018 году вышел обзор накопленного опыта применения роботов способных на социальное взаимодействие с учащимися. В обзоре выделена ключевая проблема: преподаватели-роботы должны уметь не только правильно интерпретировать ответы учащихся на предлагаемый образовательный контент, но также распознавать быстрые и невербальные социальные сигналы, которые указывают на вовлеченность в работу, замешательство и внимание [7]. Это говорит о том, что робот не сможет заменить преподавателя в ряде социогуманитарных наук, так как студенту, молодому учёному, важна обратная, живая связь и эмоции от взаимодействия с преподавателем.

Касательно вторжения в научную деятельность, ещё рано утверждать наверняка, но уже понятно, что ИИ повлияет на традиционные концепции интеллектуальной собственности. Если сегодня ИИ создаёт изобретения, пишет литературные обзоры и обрабатывает массивы научной информации, то философское осмысление слова «автор» и «авторство» в корне может трансформироваться в ближайшем будущем.

Как бы там ни было, ИИ обладает рядом важных в контексте науки и образования когнитивных функций, которые нужно учитывать всем учёным, берущимся анализировать данную тематику (таблица 1).

Исходя из таблицы видно, что сегодняшний ИИ - это венец машинной эволюции, который ориентирован на решение всех задач, которые могут возникнуть перед человеком, и осуществление всех когнитивных функций; современное поколение ИИ по ряду параметров является более жизнеспособным и мощным, чем интеллект человека.

В данном аспекте важно найти смысловой баланс и не выискивать экзистенциальные парадоксы - необходимо помнить, что основополагающими целями системы ИИ всегда было стимулирование создания новых технологий и творческих произведений, формирование устойчивой научной базы для изобретательства и творчества. С позиции философии финансов, если не принимать во внимание латентные цели системы ИИ, у нас нет причин не использовать его для стимулирования новых направлений научных изысканий, генерируемых искусственным интеллектом.

Бесспорно, широкое применение технологий ИИ в науке изменит сущность имеющихся понятий: патенты, промышленные образцы, научные произведения и т.д. На сегодняшний день этот процесс уже запущен, однако причина не только в ИИ, но и в целом в цифровизации экономики знаний. Например, в биологических науках генерируются огромные массивы данных, которые имеют значительную научную ценность, но по своей сути они не являются изобретениями в классическом понимании, поэтому важно выяснить, какие права и обязанности к ним прилагаются; именно поэтому, данная тематика является мультидисциплинарной и находится на стыке философии, психологии, права, этики, социологии и ряда смежных наук.

Важно понимать, что для активного внедрения ИИ в научную деятельность, нужна смена информационной парадигмы: именно данные являются фундаментом ИИ, поэтому они должны находиться в открытом доступе для возможности их обработки и использования в процессе генерации информации. В научном обществе по этому поводу уже сложились неоднозначные убеждения. В частности, движение за «открытость» науки, данных и публикаций пропагандирует позицию о том, что в «мире Данных» не должны применяться вещественно-правовые категории, которые носят ограничительный характер и тормозят внедрение ИИ в науку. Сторонники же разумных ограничений опасаются, что ИИ заменит научный труд неполноценным симулякром.

По нашему мнению, для того, чтобы наглядно продемонстрировать напрасность опасений, касающихся 
Преимущества искусственного интеллекта (составлено автором)

\section{Преимущества ИИ}

Восприятие, распознавание и классификация любых сигналов окружающего мира, а также информации в любом виде, наличие памяти без пробелов, обмен, анализ, сопоставление, оценка определенных данных, объективная их интерпретация.

Обобщение и использование информации для решения задач или принятия решений, обработка значительных объемов информации;

объективная, беспристрастная оценка ситуации;

выбор стратегии и тактики наиболее оптимальной формы поведения, заблаговременное планирование и ситуативная переориентация; генерирование новых знаний.

Способность самостоятельно формировать цели своего функционирования, динамически изменять содержание цели в результате изменения внутренних и (или) внешних обстоятельств (например вследствие ограничения доступа к необходимым вычислительным, энергетическим, сырьевым, финансовым и другим ресурсам, изменения окружающей среды, отказа человека от сотрудничества и т.д.).

Полная осведомленность о принципах своего построения и работы; само0бучение, саморазвитие, самоперестройка, самосовершенствование (версия ИИ отыскивает ошибки внутри себя, исправляет их, образует усовершенствованную версию самой себя и так переписывает сама себя до бесконечности), то есть способность выйти за пределы своей начальной программы. Скорость принятия решения (секунды и миллисекунды); накопление опыта, обобщение, отыскание неочевидных связей и построение логических цепочек; концентрация внимания на протяжении любого необходимого времени; построение ценностных суждений; самостоятельность принятия решений и самостоятельное их выполнение, автономность от человека; адаптация способность адаптироваться к изменяющимся требованиям окружающего мира (аккомодация) и воспроизводить во время познавательной активности отдельные характеристики объекта познания (ассимиляция).

Творчество, то есть открытие новых аспектов знания и преобразование окружающего мира (ИИ пишет музыку, дирижирует оркестром, рисует картины, публикует статьи); наличие самоорганизации.
Недостатки человеческой когниции

ИИ способен воспринимать сигналы, которые не способен обработать мозг человека; память человека не сохраняет целостные воспоминания, каждый раз припоминания извлекаются заново; память может подвергаться процессу деменции.

Беспристрастная оценка ситуации человеком порой невозможна из-за эмоциональной реакции, гормональных колебаний.

Вследствие ограничения доступа к необходимым вычислительным, энергетическим, сырьевым, финансовым и другим ресурсам человек может потерять жизненный потенциал (недостаток пищи, воды, сна).

Самосовершенствование доступно не всем людям; анализ собственных ошибок порой возможен только спустя длительное время.

Человеку необходимо время на осмысление и обдумывание; неочевидные связи могут быть не обнаружены; концентрация внимания ухудшается с уставанием и истощением мыслительных процессов по прошествии времени работы.

Человек превосходит ИИ только в данном аспекте. замены Учёного или Преподавателя искусственным интеллектом, приведём пример из другой сферы: музыкальные произведения, которые генерируются ИИ, не создаются на пустом плацдарме, то есть, на определённом этапе данного процесса, в алгоритм обязательно закладывается цифровое выражение музыки, которую уже в прошлом составил человек (Вольфганг Амадей Моцарт, Людвиг ван Бетховен, современный композитор и т.д.). Поэтому в любом случае признаётся ценность человеческого происхождения данных.

Если переложить всё это на научную деятельность, то становится очевидно, что ИИ является результатом попытки синтеза, воспроизведения тех проявлений когнитивно-интеллектуальной человеческой природы, которые уже были исследованы. Однако полнота и многогранность человеческого существования, постоянная динамичность, непредсказуемость интеллекта и принципиальное право на творческую деятельность и ментальные ошибки, делает изучение вопроса искусственного интеллекта в контексте научных изысканий спорным ввиду того, что воспроизведение имеющегося когнитивного знания, и даже вероятных схем его продуцирования, не может считаться полноценной аналогией человеческого научного потенциала.

Главная проблематика заключается в том, что ход науки обычно построен на случайностях; событие с высокой степенью неопределенности содержания и дальнейшего течения, но со значительной вероятностью наступления, N. N. Taleb именует «черным лебедем» [8]. Последним в борьбе за научную действительность и будущее может оказаться ИИ, но объект влияния такого события - наука, способна эффективно ему противостоять и выходить из-под вероятного столкновения парадигм с положительными изменениями. То есть, по нашему мнению, наука обладает признаком антихрупкости (по N.N. Taleb) - «способностью к извлечению выгоды из неудач, 
потерь, ошибок; умением закаляться, развиваться и становиться сильнее при столкновении с хаосом».

С философской точки зрения важен тот лишь факт, что ИИ не имеет человеческих принципов, на которых строится социум и в котором происходит эволюция эмотивной сферы личности. Если брать за основу тезис, что двигатель правильного вектора человеческой эволюции - не разум, а интрапсихическое ядро с обширным спектром чувств и переживаний, то можно спрогнозировать, что научно-техническая эволюция может оказаться в сенситивном тупике.

8 июня 2019 базовые принципы, регламентирующие этические проблемы в сфере ИИ были приняты на заседании министров стран G-20 (Koizumi, 2019) [9].

Базовым условием выполнения этих принципов является соблюдение человекоцентричности в применении искусственного интеллекта, что повысит доверие к нему и позволит в полной мере реализовать его потенциал. Вопрос правосубъектности ИИ также был поставлен на повестку дня, ввиду того, что уже активно аргументируются тезисы о том, что ИИ имеет все проявления когнитивных процессов, поэтому он обладает сознанием, которое подобно человеческому и нуждается в защите.

Помимо всего вышесказанного, внедрение ИИ в научную сферу невозможно без успешной реализации этапа, который предшествует любым научным изысканиям - образовательного. В контексте данного факта, необходимо провести цифровизацию всех учебных заведений - от начальной школы до университетов; средства, выделенные на образовательный сектор, должны идти на переобучение преподавателей, внедрение соответствующих классов и факультетов. Занятость и образовательная политика в эпоху искусственного интеллекта и робототехники должны перейти на новый этап развития, чтобы подготовить будущие кадры к планомерному переходу к глобальному ИИ. Программирование, робототехника и основы ИИ, создание онлайн-платформ для индивидуального обучения, привлечение инвесторов для переоборудования учебных заведений - всё это должно активно предшествовать масштабизации ИИ.

По нашему мнению, вполне реальна опасность не заметить развитие новой сингулярности: сначала человечеству лишь немногим помогал дружественный и подконтрольный слабый искусственный интеллект, но затем мозг каждого человека стал буквально совмещенным с глобальным ИИ, так как уже сегодня многие люди не могут ориентироваться в окружающей реальности без помощи цифровых технологий и интернета, что превращает личностный интеллект каждого в некую мутационную структуру и способствует появле- нию виртуального неокортексного облака.

Утверждение «человек - высшее звено эволюции и другого быть не может», опирается на подобное спорное философское утверждение «только человек имеет душу и сознание» (хотя с выявлением и анализом последних тоже возникают проблемы, например, «концепция сознания, имеющая нефизическую природу, открывает новые возможности для интерпретации квантовой механики и конструирования сознательных роботов» [10, с. 441]). Но правда заключается в том, что технологический мир и не пытается воспроизвести душу, а вот превзойти интеллект человека по ряду параметров, - является задачей уже давно достигнутой.

Нерешенной частью общей проблемы остается отсутствие надлежащего научного обоснования последствий применения искусственного интеллекта в образовании и науке в контексте этики его использования, а также влияния на общественные отношения. Указанное может стать определяющим этапом дальнейшего развития ИИ в истории образования и науки.

Исследовать ИИ в контексте всего вышесказанного важно своевременно, так как в настоящее время происходит активное развитие научного знания. Наука, обогащаясь эмпирическими данными, формирует новые идеи, концепции, гипотезы, теории, парадигмы. Во время размышлений человек может удерживать в своем сознании не больше семи или девяти объектов и учитывать не более трех или четырех параметров для выводов. Это выглядит очень примитивно по сравнению с алгоритмами, которыми оперирует ИИ с неограниченным их количеством. Поэтому рассматривать искусственный интеллект с антропоморфной точки зрения является безосновательным.

\section{ВывоАь}

1. Важно найти смысловой баланс и не выискивать экзистенциальные парадоксы - необходимо помнить, что основополагающими целями системы ИИ всегда было стимулирование создания новых технологий и творческих произведений, формирование устойчивой научной базы для изобретательства и творчества.

2. На сегодняшний день нет причин не использовать ИИ для стимулирования новых направлений научных изысканий, генерируемых искусственным интеллектом.

3. В любом случае, воспроизведение имеющегося когнитивного знания и даже вероятных схем его продуцирования, не могут считаться полноценной аналогией человеческого научного потенциала.

4. Безстрессовое внедрение ИИ в научную сферу невозможно без успешной реализации этапа, кото- 
рый предшествует любым научным изысканиям - образовательного. В контексте данного факта, необходимо провести цифровизацию всех учебных заведений - от начальной школы до университетов. Занятость и образовательная политика в эпоху искусственного интеллекта и робототехники должны перейти на новый этап развития, чтобы подготовить будущие кадры к планомерному переходу.

5. Нерешенной частью общей проблемы остается отсутствие надлежащего научного обоснования последствий применения ИИ в образовании и науке в контексте этики его использования, а также влияния на общественные отношения, их эмоциональные и нравственные устои, которые могут быть поставлены под угрозу; указанное может стать определяющим этапом дальнейшего развития ИИ в истории образования и науки.
6. Для науки и образования Российской Федерации нам видится единственно возможный положительный сценарий в рамках исследуемой темы: будет продолжать развиваться научно-ориентированная интерактивная среда обучения всех уровней (от дошкольного до ВУЗовского и последипломного), позволяющая учащимся и молодым учёным получать опыт научно-исследовательской деятельности с использованием ИИ, путем использования инновационных методов обучения, только лишь как вспомогательных; преподавателям же ИИ поможет организовать процесс обучения оптимальным для них образом и будет способствовать перераспределению рабочего времени - переходу от многочасовой рутинной работы к более плодотворному личностному взаимодействию со студентами, без которого невозможен образовательный процесс.

\section{ЛИТЕРАТУРА}

1. Бегишев И.Р., Латыпова Э.Ю., Кирпичников Д.В. Искусственный интеллект как правовая категория: доктринальный подход к разработке дефиниции // Актуальные проблемы экономики и права. 2020. №1. URL: https://cyberleninka.ru/article/n/iskusstvennyy-intellekt-kak-pravovaya-kategoriya-doktrinalnyypodhod-k-razrabotke-definitsii (дата обращения: 05.06.2020).

2. Пырнова 0.А., Зарипова Р.С. Технологии искусственного интеллекта в образовании // Russian Journal of Education and Psychology. 2019. №3. URL: https:// cyberleninka.ru/article/n/tehnologii-iskusstvennogo-intellekta-v-obrazovanii (дата обращения: 07.06.2020).

3. Пичужкина Д.Ю., Смекалова Е.С., Сулима И.И. Искусственный интеллект: возможности в системе образования // Наука и образование: новое время. 2019. №. 1. C. 619-623.

4. Cadets introduced to the future of Artificial Intelligence // Pointer View. The serving the U.S. Military Academy and the Community of West Point. September 21, 2017. Vol. 74. No. 37. P. 2.

5. Тихонова Л.П. Моделирование функциональных возможностей цифрового ассистента и условий его реализации в вузовском учебном процессе // Вестник Череповецкого государственного университета. 2019. №4 (91). URL: https://cyberleninka.ru/article/n/modelirovanie-funktsionalnyh-vozmozhnosteytsifrovogo-assistenta-i-usloviy-ego-realizatsii-v-vuzovskom-uchebnom-protsesse (дата обращения: 18.06.2020).

6. Тихонова Л.П. 06 актуальности внедрения современных цифровых технологий в образование // Вестник Череповецкого государственного университета. 2019. №1 (88). URL: https://cyberleninka.ru/article/n/ob-aktualnosti-vnedreniya-sovremennyh-tsifrovyh-tehnologiy-v-obrazovanie (дата обращения: 18.06.2020).

7. Belpaeme T. et al. Social robots for education: A review. Science robotics. 2018. T. 3. No. 21. P. 1.

8. Taleb N. N. The black swan: The impact of the highly improbable. Random house, 2007. T. 2. P. 210.

9. IPQUORUM 10-12 апреля 2019 (Москва). «Ipchain Legaltech Review» 2019. URL: https://ipchain.ru/docs/legal_review_june.pdf (дата 0бращения: 06.06.2020).

10. Белокопытов Ю.Н., Панасенко Г.В. Сознание за гранью искусственного интеллекта? // Наука и образование: опыт, проблемы, перспективы развития. 2019. C. 440-444.

(с Евсюк Александр Владимирович (avev2020@bk.ru).

Журнал «Современная наука: актуальные проблемы теории и практики» 